\author{
Mirko Mikić \\ Arheološki institut Beograd \\ Vojislav Stojanović \\ Arheološki institut Beograd \\ Nemanja Mrđić \\ Arheološki institut Beograd
}

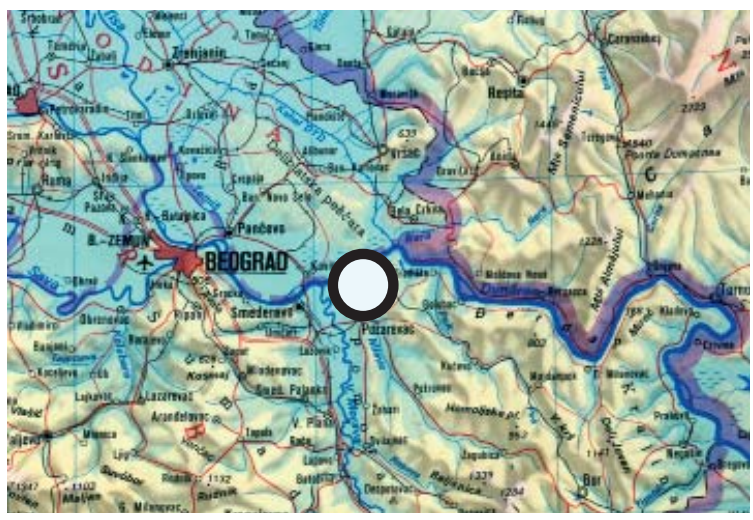

Viminacium, Stari Kostolac, Srbija

LAT 44 44'09" / LONG $21^{\circ} 12^{\prime} 42^{\prime \prime}$

\title{
PRIMENA GRADIOMETRA ZA POTREBE ZAŠTITNIH ARHEOLOŠKIH ISTRAŽIVANJA NA VIMINACIJUMU - LOKALITET RIT
}

\begin{abstract}
ABSTRAKT
Zaštitnim arheološkim radovima na lokalitetu Rit prethodila su obimna geofizička istraživanja. Rezultati dobijeni ovim radovima omogućili su detaljno planiranje iskopavanja i postavljanje sondi. Na prostoru koji je površine 4 hektara, definisan je prazan prostor, a istraživanje usmereno na otkriveni kompleks objekata. Saznanja dobijena arheološkim iskopavanjem potvrdila su i dopunila interpretaciju geofizičkih rezultata i postavila standarde za buduća istraživanja.
\end{abstract}

KLJUČNE REČI: VIMINACIJUM, GRADIOMETAR, GEOFIZIKA, ARHEOLOGIJA

Viminacijum, ${ }^{1}$ rimski grad i vojni logor prostire se na površini većoj od 80 ha. Zajedno sa pristaništem, nekropolama i drugim prigradskim zonama zahvata preko 400 hektara. Sama činjenica da na tom prostoru grad više nije obnovljen, kao i da je danas to poljoprivredno zemljište, čini ga veoma pogodnim za arheološka i geofizička istraživanja. Da bi se dopunila arheološka rekognosciranja i umanjila mogućnost

1. Podaci i snimci predstavljeni u radu deo su terenske dokumentacije Arheološkog instituta. Istraživanjima, koja su vršena tokom 2004 - 2005. godine rukovodio je dr Miomir Korać. Autori rada su deo stručne ekipe Arheološkog instituta koja je vršila istraživanja. M. Mikić i V. Stojanović su inženjeri geofizike. Arheološki deo ekipe činili su mr B. Milovanović i N. Mrđić. Izveštaj sa iskopavanja, materijal i dalja interpretacija biće deo posebne studije koja je u pripremi. praznih sondi, prethodno su izvršena geofizička istraživanja. Ovakva metodologija se pokazala veoma uspešnom i dala je odlične rezultate, skraćujući vreme potrebno za iskopavanja.

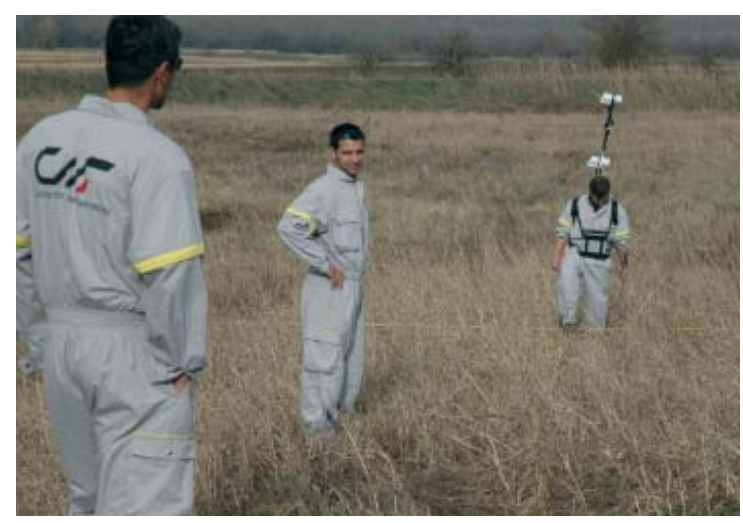

Geomagnetska akvizicija pomoću gradiometra 
Geomagnetska metoda se poslednjih godina često koristi u arheološkoj prospekciji, naročito zbog visokih gradijenata koje daje u sredinama koje su bogate arhitekturom i predmetima od pečene zemlje (opeka, veće koncentracije keramike itd).

\section{LOKACIJA I USLOVI ISTRAŽIVANJA}

Deo lokaliteta Rit ugrožen je kopanjem bunara i kanala cevovoda LB-5 za potrebe površinskog kopa "Drmno" (Sl. 1). Da bi se smanjila mogućnost oštećenja arheoloških ostataka zbog obimnih građevinskih radova, izvršena su geofizička istraživanja ugroženog područja, koje se nalazi $300 \mathrm{~m}$ istočno od severoistočnog ugla kastruma VII Klaudijeve legije (Legio VII Claudia Pia Fidelis). Sistematsko razgrađivanje antičkih objekata na celom Viminacijumu dovelo je do toga da su od njih ostali očuvani samo temelji ili niži delovi zidova u zemlji. Na ugroženom prostoru mestimično su se mogli uočiti tragovi građevinskog šuta, ali pošto se radi o njivama koje su intenzivno obrađivane bilo je jasno da je materijal razvučen oranjem. Antički objekti mogli su se ubicirati u radijusu od najmanje 20 metara što za potrebe ovih radova nije bilo dovoljno. Prethodna arheološka kao i geofizička istraživanja na tom prostoru nisu bila vršena.

Pošto su u pitanju bili zaštitni radovi postojali su određeni vremenski rokovi. To je nametnulo potrebu da se objekti precizno lociraju i definišu u što kraćem vremenskom periodu. Sondažnom arheološkom iskopavanju prethodilo je sistematsko geofizičko snimanje terena.

\section{PRIKUPLJANJE I OBRADA PODATAKA}

Geomagnetska akvizicija je vršena korišćenjem protonskog magnetometra - gradiometra sa Overhauzerovim efektom (GEM Systems, model GSM$19 \mathrm{GW}$ ) za pokrivanje površine od $35200 \mathrm{~m}^{2}$.

Ugroženi prostor je podeljen na 88 polja dimenzija 20 x 20 m. Terenska sredstva kao merne trake, kočići, itd., napravljeni su od nemagnetičnih

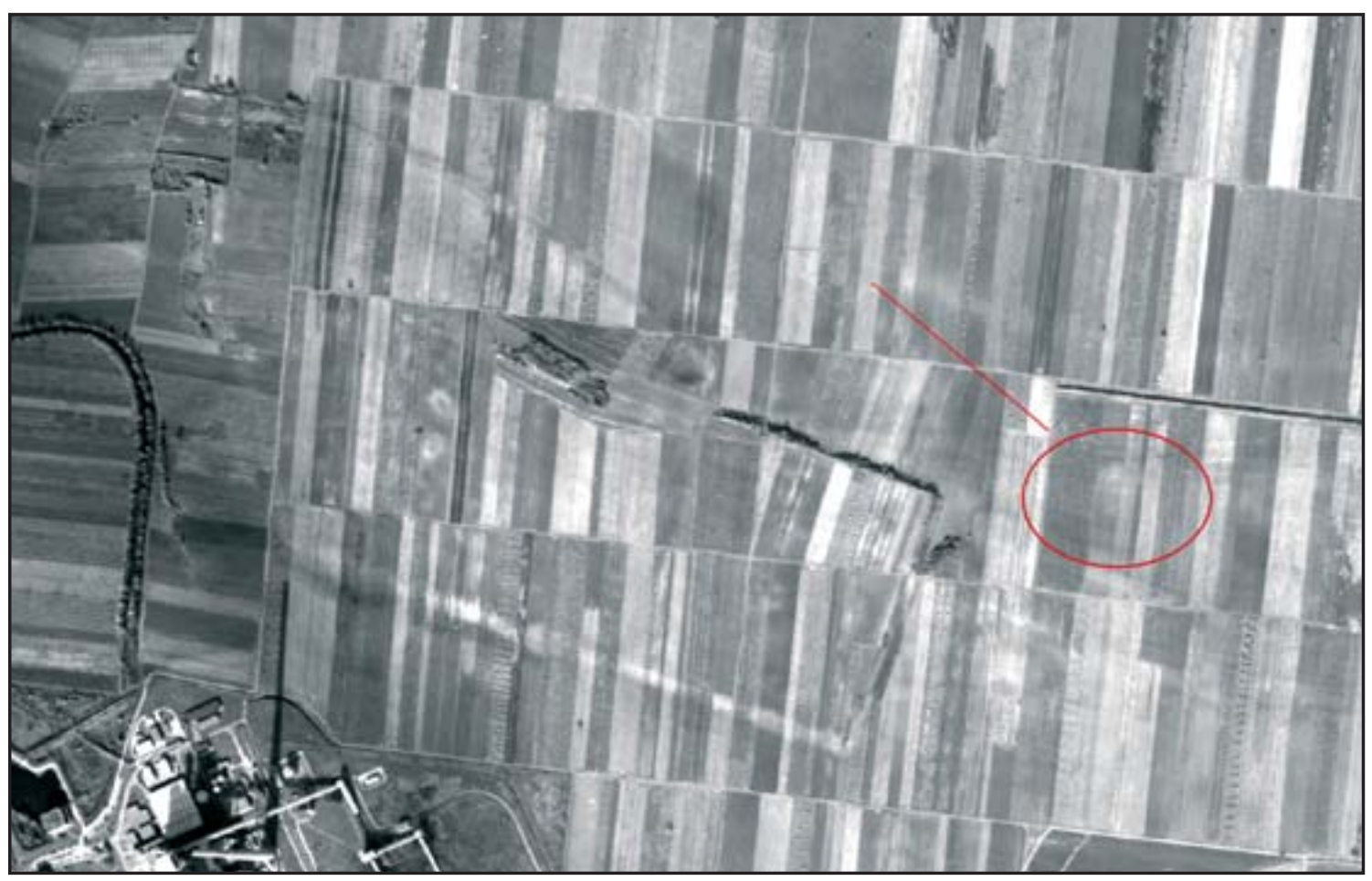

Slika 1. Aerosnimak Viminacijuma sa naznačenom zonom istraživanja 
materijala. Trake su markirane na rastojanju od 1 $m$ radi preciznijeg i bržeg istraživanja. Sam instrument je kalibrisan fabrički i podešen na osetljivost od $0.017 \mathrm{nT}$. Visina instrumenta u odnosu na površinu terena je $2 \mathrm{~m}$ zbog najboljeg odnosa signal/smetnja. Radi što bolje rezolucije podataka instrument je ručno podešen na 2 čitanja u sekundi. Merenja počinju iz gornjeg desnog ugla istraženog područja paralelnim profilima na rastojanju od $1 \mathrm{~m}$ sa smerom kretanja sever - jug. Podaci su nakon merenja prenošeni sa interne memorije instrumenta na računar radi dalje obrade i interpretacije. Sama obrada obuhvata unošenje podataka u softverski paket i interpolaciju primenom tačkastog Kriging-a sa linearnim modelom variograma i intervalom interpolacije od $0.1 \mathrm{~m}$. Rezultati istraživanja su prikazani u vidu geomagnetske karte vertikalnog gradijenta u opsegu od -6.0 do $+6.0 \mathrm{nT}$, gde su minimalne vrednosti prikazane belom, maksimalne crnom, a vrednosti unutar opsega nijansom sive boje. Karta je georeferencirana i pozicionirana na aerosnimak kao podlogu.

\section{INTERPRETACIJA GEOFIZIČKIH REZULTATA}

Primena geomagnetske metode na područje predviđeno za projektovanje linije cevovoda dala je izuzetno dobre rezultate (sl. 2). Istražno područje je većim delom mirno u pogledu vrednosti magnetnog gradijenta, dok se u centralnom delu uočavaju anomalije koje svojim rasporedom i intenzitetom ukazuju na postojanje ostataka arhitekture. Na karti magnetnog polja uočavaju se linearne paralelne karakteristike sa pravcem pružanja istok - zapad. Tamnije karakteristike koje se nalaze u centralnom delu istražnog područja predstavljaju pozitivne vrednosti magnetnog gradijenta prouzrokovane ostacima od opeke i zapečene zemlje koje upućuju na postojanje zidova većeg objekta i mogućeg ogradnog zida dimenzija $32 \times 22 \mathrm{~m}$. $\mathrm{U}$ njegovom centralnom delu uočava se pozitivna anomalija jačeg inteziteta što može ukazati na

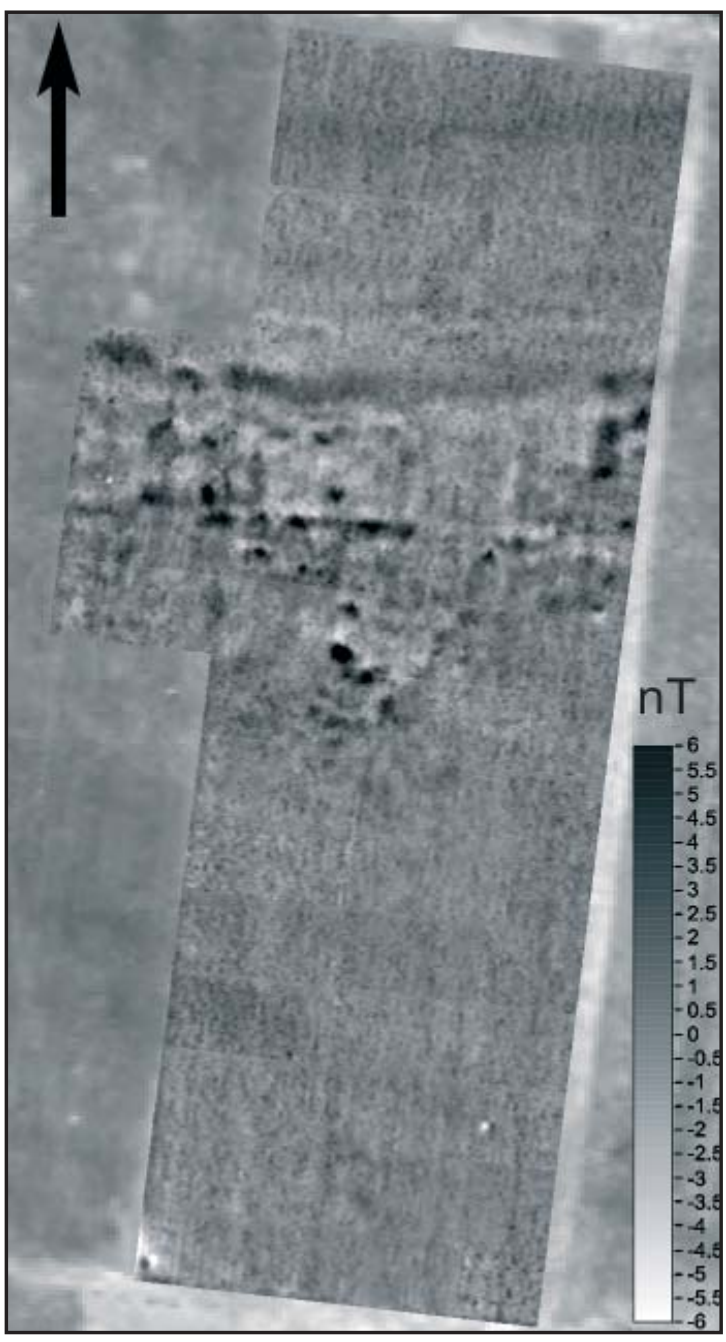

Slika 2. Rezultati geofizičkih snimanja

postojanje koncentrisanog zapečenog materijala unutar objekta. Lokacija ove anomalije - objekta označena je plavom bojom na tabli 3. Arheološka iskopavanja potvrdila su da se u tom delu nalazi prostorija sa potpornim stupcima za podno grejanje - sistem hipokausta (slika 3). Tamni lineament u severnom delu istražnog područja sa pravcem pružanja istok - zapad koji oivičava objekte sa severne strane, ukazuje na recentnu komunikaciju što je dokazano sondažnim iskopavanjem i daljinskom detekcijom vršenoj na bazi avio snimka iz 1967. godine sa prethodnom parcelacijom ovog područja. ${ }^{1}$ Usled veoma kratkog roka za istraživanja, arheološke sonde su otvarane na najugroženijim mestima. Za anomalije sličnog tipa koje nisu sondirane možemo dati geofizičku

1. Na slici 3 označeno je crvenom bojom. 
interpretaciju, sa pretpostavkom o postojanju objekata, na osnovu nalaza u arheološkim sondama u neposrednoj blizini. Žutom bojom je označena pretpostavljena arhitektura u vidu spoljnih zidova (sl. 3).

\section{REZULTATI ARHEOLOŠKIH IS- KOPAVANJA I ZAKLJUČNO RAZMA- TRANJE}

Arheološkim istraživanjima potvrđeno je postojanje najmanje dva, a verovatno tri objekta u okviru kompleksa ograđenog zidom dimenzija 32 x $22 \mathrm{~m}$ i jednog manjeg objekta udaljenog oko $50 \mathrm{~m} \mathrm{ka}$ istoku.

$\mathrm{U}$ sondama postavljenim $\mathrm{u}$ istočnoj zoni otkriven je velik broj pokretnih nalaza. Arhitek- tonski ostaci konstatovani su samo u negativu, ali je potvrđeno postojanje objekta na tom prostoru. Dalju interpretaciju moguće je delimično sprovesti prema osnovi dobijenog geomagnetnog snimka. ${ }^{1}$

U centralnom delu snimane površine, konstatovan je kompleks ograđen zidom od kamena ${ }^{2}$. Ostaci ogradnog zida, širine oko $1 \mathrm{~m}$, u znatnoj meri devastiranog, otkriveni su u jednoj od sondi (sl. 4). Ugao ovog zida (?) pronađen je u sledećoj sondi, ali samo u negativu. Unutar kompleksa otkrivena su najmanje dva objekta. Zidovi su nađeni na dubini od svega $0,40 \mathrm{~m}$. Na podove se naišlo već na dubini od 0,60 m. Ostaci arhitekture su slabo očuvani. ${ }^{3}$ Objekat 1 je manji, građen od kamena

1. Na slici 3. objekat krajnje desno. Gabarit je označen žutom linijom.

2. Na slici 3. pravougaonik plave boje.

3. Građevine rimskog Viminacijuma korišćene su ve-

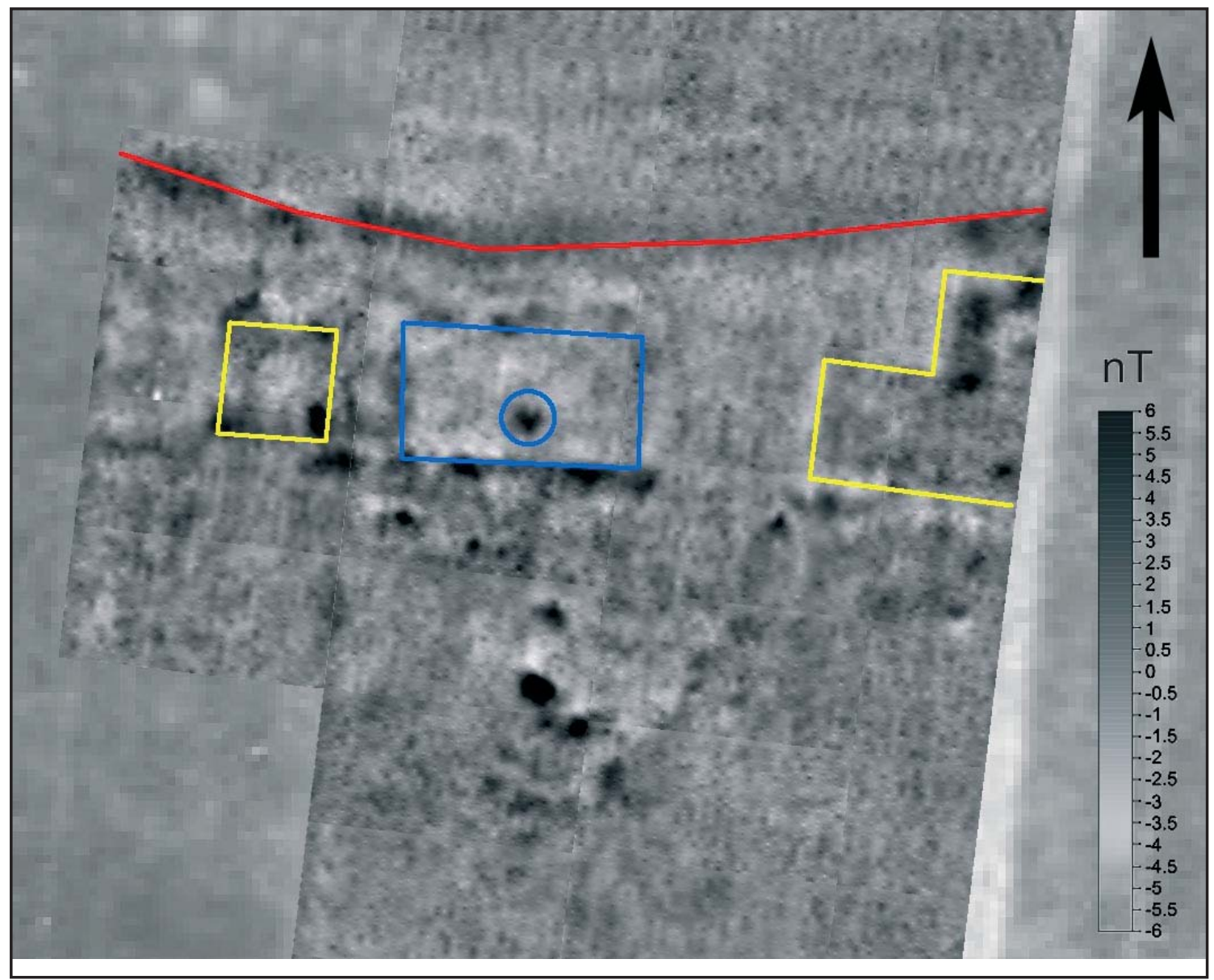

Slika 3. Interpretacija rezultata dobijena geofizičkim istraživanjima 
vezanog malterom $u$ alternaciji sa redovima opeke (opus mixtum). Očuvan je deo poda od malih heksagonalnih pločica. Objekat 2 je veći, imao je popločanje od kvadratnih opeka dok su zidovi bili od kamena vezanog krečnim malterom. ${ }^{4}$ Ostalo je kovima kao izvor besplatnog građevinskog materijala. Danas se na terenu uočavaju grube konture grada, ali se na površini ne vide objekti.

4. Visina očuvanih zidova je bila toliko mala da nije bilo nejasno da li je prostorija, sa razrušenim zidom objekta, u kojoj su konstatovani dobro očuvani stupci hipokausta deo veće zgrade (objekat 2) ili se radi o trećem objektu (sl. 4). Pošto iznad hipokausta nije očuvan pod, a vrh stubaca je značajno iznad nivoa popločanog poda udaljenog 12 metara, skloni smo

moguće utvrditi da li je i ovaj objekat građen u tehnici opus mixtum.

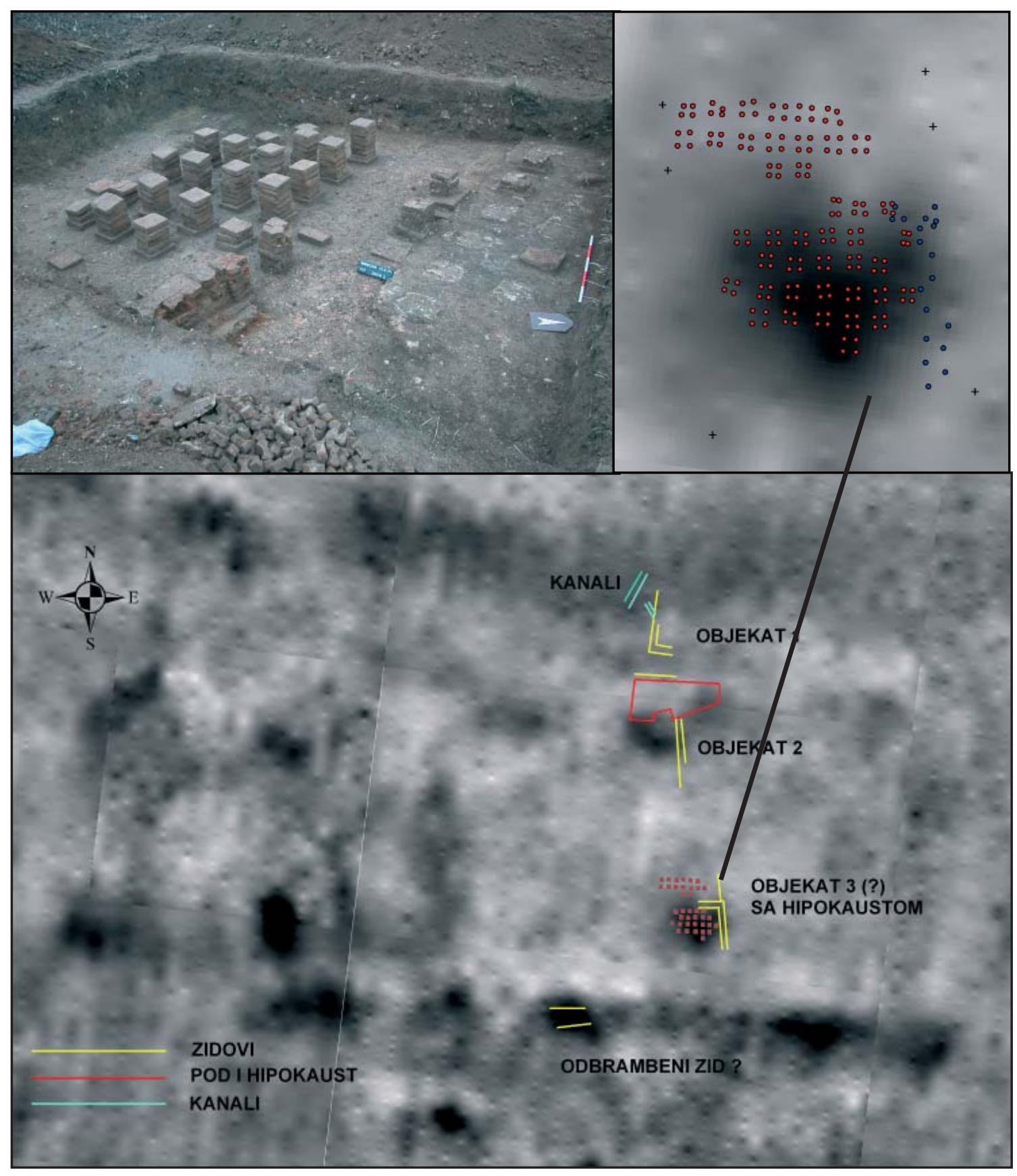

Slika 4. Istraženi objekti na lokalitetu Rit sa izdvojenim detaljima hipokausta 
pretpostavci da je reč o trećem objektu. Prilikom istraživanja prostorije sa sistemom podnog grejanja (objekat 3?) otkriveno je više stotina leptirastih podnih pločica koje su činile dekorativni pod nad hipokaustom.

Šest metara severno od objekta 2 otkriven je oštećeni veći kanalizacioni kanal koji je mogao odvoditi otpadne vode iz ove građevine. Drugi, manji kanal, izlazi iz objekta 1 i uliva se u veći koji nastavlja ka severu prateći pad terena. Na taj način je obezbeđen odliv vode slobodnim padom. Trasa se ne prati dugo, jer su ostaci uništeni oranjem i razvučeni po širem prostoru.

Istraživanje poslednjeg objekta, ${ }^{1}$ koje se na gradiometarskom snimku oslanja na ograđeni kompleks sa zapada, nije sprovedeno jer nije bio neposredno ugrožen. Njegova arheološka interpretacija izvedena je isključivo na osnovu geofizičkih rezultata, a prema analogijama sa iskopanim objektima.

\section{$* * *$}

Rezultati dobijeni arheološkim iskopavanjem omogućili su nam da odredimo referentne vrednosti arhitektonskih ostataka koje se reflektuju prilikom geomagnetskih snimanja. Na taj način će podaci dobijeni budućim akvizicijama gradiometra moći da se interpretiraju kao zidovi od kamena, opeke, šut od rasturenih opeka, površina sa zapečenom zemljom i kao što se pokazalo, hipokaust. Instrument je različito reagovao na deo hipokausta gde su očuvani stupci od onog gde su ostali samo u negativu (sl. 3).

Interpretacijom anomalija geomagnetskog polja istražnog područja omogućeno je bolje rešenje u projektovanju linije cevovoda. Pružen je uvid u izgled arhitektonskih ostataka i sagledavanje daleko šire situacije od one koja je iskopavanjem istražena. Samo arheološka iskopavanja, u ovom slučaju, dala bi nepotpune i fragmentarne podatke na osnovu male iskopane površine. Geofizička

1. Objekat krajnje levo na slici 3 i 4 . Na snimku u osnovi ima formu tetrapilona. Svaki od pilona bi mogao biti kvadratni sa dimenzijama stranice od 2-3 m. Građeni su najverovatnije od opeke i u manjoj meri od kamena. istraživanja su svojom brzinom i rezultatima uštedela vreme i fokusirala arheološka istraživanja na najinteresantnije delove terena ugrožene linijom cevovoda. Nakon geofizičkih i arheoloških istraživanja linija cevovoda pomerena je u odnosu na projektovanu trasu da bi u što manjoj meri došlo do oštećenja arheoloških ostataka.

\section{RESUME \\ Use of Gradiometer during Protective Archaeological Research at Vimina- cium, Site Stig}

Systematic geophysical survey was undertaken before protective archaeological excavations on site Rit, 300 meters to the north-east of Roman military camp at Viminacium. Data acquired during this survey enabled detailed planning and positioning of trenches for archaeological research. On the area covering 4 hectares, clear area was determined and excavations were focused on discovered complex of buildings. Results of archaeological excavations confirmed and improved interpretation of geophysical results. That helped to set standard for all future research. Images shown on geophysical plans and photographs from the excavations present results on which area that is not excavated can be interpreted solely on the base of geophysical survey.

Translated by N. Mrđić 